\title{
MHC Class I Presented T Cell Epitopes as Potential Antigens for Therapeutic Vaccine against HBV Chronic Infection
}

\author{
Joseph D. Comber, ${ }^{1}$ Aykan Karabudak, ${ }^{1}$ Vivekananda Shetty, ${ }^{2}$ \\ James S. Testa, ${ }^{3}$ Xiaofang Huang, ${ }^{1}$ and Ramila Philip ${ }^{1}$ \\ ${ }^{1}$ Immunotope, Inc., Doylestown, PA 18902, USA \\ ${ }^{2}$ Baylor College of Medicine, Houston, TX 77030, USA \\ ${ }^{3}$ Celldex Therapeutics, Hampton, NJ 08827, USA \\ Correspondence should be addressed to Ramila Philip; rphilip@immunotope.com
}

Received 6 March 2014; Revised 9 April 2014; Accepted 18 April 2014; Published 26 May 2014

Academic Editor: Piero Luigi Almasio

Copyright (C) 2014 Joseph D. Comber et al. This is an open access article distributed under the Creative Commons Attribution License, which permits unrestricted use, distribution, and reproduction in any medium, provided the original work is properly cited.

\begin{abstract}
Approximately 370 million people worldwide are chronically infected with hepatitis B virus (HBV). Despite the success of the prophylactic $\mathrm{HBV}$ vaccine, no therapeutic vaccine or other immunotherapy modality is available for treatment of chronically infected individuals. Clearance of HBV depends on robust, sustained CD8 ${ }^{+} \mathrm{T}$ activity; however, the limited numbers of therapeutic vaccines tested have not induced such a response. Most of these vaccines have relied on peptide prediction algorithms to identify MHC-I epitopes or characterization of T cell responses during acute infection. Here, we took an immunoproteomic approach to characterize MHC-I restricted epitopes from cells chronically infected with HBV and therefore more likely to represent the true targets of $\mathrm{CD}^{+} \mathrm{T}$ cells during chronic infection. In this study, we identified eight novel MHC-I restricted epitopes derived from a broad range of $\mathrm{HBV}$ proteins that were capable of activating $\mathrm{CD}^{+} \mathrm{T}$ cells. Furthermore, five of the eight epitopes were able to bind HLA-A2 and A24 alleles and activated HBV specific T cell responses. These epitopes also have potential as new tools to characterize $\mathrm{T}$ cell immunity in chronic HBV infection and may serve as candidate antigens for a therapeutic vaccine against HBV infection.
\end{abstract}

\section{Introduction}

Hepatitis B virus (HBV) is a member of the Hepadnaviridae family of viruses which also includes woodchuck hepatitis virus (WHV) and duck hepatitis B virus. These viruses are primarily hepatotropic with infections characterized by fever, fatigue, muscle aches, and yellowing of the eyes and/or skin. The severity of these symptoms can vary with a proportion of cases being asymptomatic [1]. More than 2.5 billion people worldwide have been infected by HBV, but, for the vast majority of adults encountering the virus $(>90 \%)$, the infection is acute and readily cleared by the immune system $[2,3]$. For the remaining $5-10 \%$ of adults, and for neonates and unvaccinated children, HBV establishes a chronic infection. Approximately 370 million people worldwide are chronically infected and over 500,000 people die each year due to complications from HBV $[1,4]$. These complications include liver cirrhosis, liver failure, and/or hepatocellular carcinoma
(HCC) and it is estimated that up to $40 \%$ of chronically infected patients will develop at least one of these complications [5].

The primary determinant of whether hepatitis B virus is cleared or establishes a chronic infection is the robustness of the immune response, in particular the $\mathrm{CD} 8^{+} \mathrm{T}$ cell response [6-9]. Data from both animal models and infected patients indicate that strong innate immune responses are crucial in controlling initial HBV replication and for subsequently activating the adaptive $\mathrm{T}$ cell response (reviewed in $[2,3]$ ). In patients that resolve acute infections, there are greater numbers of IFN- $\gamma$ secreting $\mathrm{CD}^{+}$and $\mathrm{CD}^{+} \mathrm{T}$ cells [10] with a broader range of epitope recognition [11, 12] than in chronically infected patients $[3,13]$. Although individuals that initially fail to mount vigorous $\mathrm{T}$ cell responses develop chronic infection, data indicate that virus specific $\mathrm{T}$ cells are still capable of a broad, effective $\mathrm{T}$ cell response. Rehermann et al. demonstrated that a small number of 
chronically infected individuals mount robust CTL responses against HBV either spontaneously or in response to IFN- $\alpha$ treatment [14]. These $\mathrm{T}$ cells are directed against multiple proteins indicating that chronically infected patients can also mount a broad response to viral antigens. These data suggest that therapeutic interventions designed to stimulate robust and multiepitope specific responses may be sufficient to resolve chronic HBV infections. Yet, despite an effective prophylactic vaccine, there are currently no therapies capable of eliminating HBV from chronically infected individuals. A number of anti-HBV therapeutic vaccines have been tested including traditional prophylactic vaccines, antigen/antibody complexes [15], lipopeptide [16], DNA [17], and recombinant virus [18] based strategies with limited success. Thus, there is a critical need for more targeted therapeutic vaccines capable of inducing robust, sustained $\mathrm{T}$ cell responses capable of permanent clearance of virus.

Therapeutic peptide based vaccines are an attractive method for inducing $\mathrm{CD}^{+}$and $\mathrm{CD}^{+} \mathrm{T}$ cell responses in chronically infected individuals. Formulating a vaccine with multiple epitopes presented by the chronically infected cells that are capable of activating polyclonal $\mathrm{T}$ cell responses may have the ability to eradicate the infected cells in chronically infected patients. Peptide antigens for the early stage clinical studies were identified by motif prediction algorithms and selected by screening CTLs from acute and chronically HBV infected patients [19]. However, the T cell epitopes presented by HBV infected cells have not been reported or used in a clinical study. Here we took an immunoproteomic approach to identify MHC class I peptides presented by chronically HBV infected cells. This approach has distinct advantages over traditional vaccine design algorithms as it identifies antigens naturally processed and presented by infected, but not healthy, cells. Using this approach we identified 8 naturally processed HLA-A2 restricted epitopes capable of stimulating robust $\mathrm{CD}^{+} \mathrm{T}$ cell responses. Interestingly a subset of these epitopes is also capable of binding HLAA24 molecules and stimulates both HLA-A2 and HLA-A24 restricted $\mathrm{T}$ cell responses.

\section{Materials and Methods}

2.1. Mice. Four- to eight-week-old female HLA-A2 transgenic (CB6F1-Tg(HLA-A * 0201/H2-K $\left.{ }^{\mathrm{b}}\right) \mathrm{A}^{*}$ 0201) or HLA-A24 transgenic (CB6F1-Tg(HLA-A* 2402/H2-K $\left.\left.{ }^{\mathrm{b}}\right) \mathrm{A} 24.01\right)$ mice were obtained from Taconic and housed at Lampire Biologicals (Pipersville, PA). All animal experiments were conducted in adherence to the Guide for Care and use of Laboratory Animals of the NIH. Experimental protocols were approved by the Institutional Animal Care and Use Committee of Lampire Biologicals.

2.2. Cells, Viruses, and Plasmids. The HLA-A2 and A24 positive liver hepatocellular carcinoma cell line HepG2 and its hepatitis B infected derivatives HepDE19 and HepG2.2.15 were cultured in Dulbecco's Modified Eagle Medium/Ham's F-12 50/50 Mix (Mediatech Inc, Manassas VA). 293-T cells were maintained in Dulbecco's' Modified Eagle Medium and T2 cells were maintained in RPMI-1640 (Mediatech Inc). All media were supplemented with $10 \%$ fetal bovine serum (Atlanta Biologicals, Flowery Branch, GA), L-glutamine (300 mg/mL), 1x nonessential amino acids, $0.5 \mathrm{mM}$ sodium pyruvate, and $1 \mathrm{x}$ penicillin/streptomycin (Mediatech Inc). Cells were maintained at $37^{\circ} \mathrm{C}$ and $5 \% \mathrm{CO}_{2}$.

Adenovirus containing the HBV genome (Ad-HBV) was a kind gift of Dr. Anand Mehta (Drexel University). 293THLA.A $2^{+}$cells were seeded into 6 -well plates and infected with AdHBV virus. 48-72 hours later, the cells were harvested and used in downstream applications.

2.3. Isolation, Purification, and Fractionation of MHC Class I Bound Peptides. Hepatitis B virus specific MHC class I restricted peptides were isolated as previously described [20]. Briefly, $1 \times 10^{9}$ HepDE19 cells were lysed $(150 \mathrm{mM} \mathrm{NaCl}$, $10 \mathrm{mM} \mathrm{Na}_{2} \mathrm{HPO}_{4}, 1 \mathrm{mM}$ EDTA, 1\%NP40) and peptide/MHC complexes ( $\mathrm{p} / \mathrm{MHC}$ ) were immunoprecipitated using protein A/G beads (UltraLink Immobilized Protein A/G, Pierce, Rockford, IL) coated with W6/32, a monoclonal antibody that recognizes pan-MHC class I molecules. Antibody coated beads were incubated with cell lysate for 2 hours with rocking and then separated from the lysate by centrifugation (1000 rpm/5 min). The $\mathrm{p} / \mathrm{MHC}$ complexes were eluted from the beads using $0.1 \%$ trifluoroacetic acid and the peptides were dissociated from the MHC molecules by heating at $85^{\circ} \mathrm{C}$ for 15 minutes. The mixture was cooled and the peptides separated using an Amicon Ultra-3 kDA filter (Millipore, Billerica, MA). The resulting peptide mixture was then fractionated using a $\mathrm{C}-18$ reversed phase (RP) column on an offline 3000 HPLC (Dionex).

2.4. Mass Spectrometry Analysis. Mass spectrometry experiments were carried out using Orbitrap instruments (Thermo Electron, San Jose, CA) interfaced with nano ultimate highperformance liquid chromatography (HPLC; Dionex). RPHPLC-purified peptide fractions were injected individually into the LC-MS/MS system to identify the sequences [20, 21] of the peptides. The peptides were concentrated using a $300 \mu \mathrm{m}$ ID $\times 5 \mathrm{~mm}$ C18 RP trap column (Dionex) and separated using a $75 \mu \mathrm{m} \mathrm{ID} \times 15 \mathrm{~cm} \mathrm{C18} \mathrm{RP} \mathrm{analytical} \mathrm{column}$ (Dionex), equilibrated in $4 \% \mathrm{ACN} / 0.1 \% \mathrm{FA}$ at $250 \mathrm{~nL} / \mathrm{minute}$ flow rate. Mobile phase A was $2 \% \mathrm{ACN}$ and $0.1 \% \mathrm{FA}$ in water, whereas mobile phase B was $0.1 \% \mathrm{FA}$ and $90 \% \mathrm{ACN}$ in water. Peptides were separated with a gradient of $4 \%-50 \%$ B in 60 minutes and $50 \%-80 \%$ in 90 minutes and eluted directly into the mass spectrometer. Peptides were analyzed using a datadependent method. The acquired spectra data were searched against HBV protein database using Proteome Discoverer 1.3 (Thermo) to interpret data and derive peptide sequences. The database search parameters were enzyme-no enzyme, threshold-100, peptide tolerance- 20 ppm, and fragment ion tolerance- $0.8 \mathrm{Da}$. The search results were filtered with XCorr according to individual peptide charge status $(+1: 1.6,+2: 1.8$, and $+3: 2.0)$ and the results were also verified manually to confirm the correct peptide sequence. 


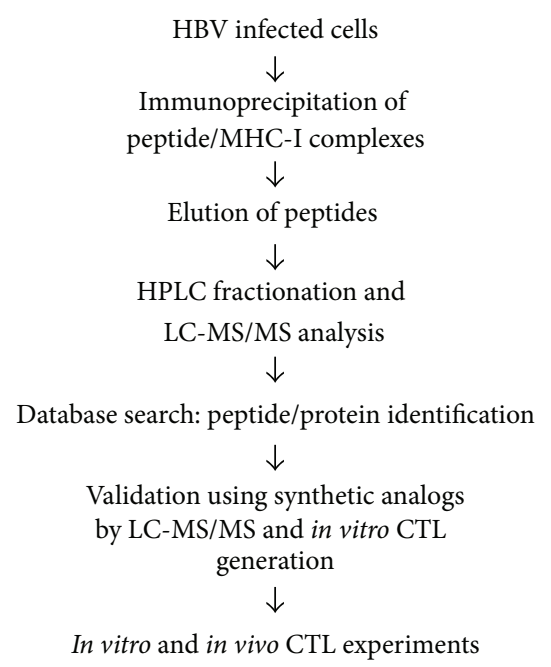

FIGURE 1: Immunoproteomics method work flow for the identification and characterization of HBV specific $\mathrm{T}$ cell epitopes.

2.5. Peptide Validation by Synthetic Peptides. Synthetic peptides for validating the peptides identified in this study were obtained from GenScript Corporation and China peptides Co., Ltd. The synthetic peptides were subjected to LC-MS/MS analysis under identical experimental conditions as described above, and their sequences were confirmed based on their MS/MS data. Candidate peptide sequences were confirmed by comparison of MS/MS spectra with synthetic analogues.

2.6. Generation of Epitope Specific CTLs In Vitro. Peptide specific CTLs were generated as previously described [2023]. Briefly, PBMCs were isolated from heparinized blood of healthy HLA-A2 $2^{+}$donors (Research Blood Components, LLC, Boston MA) using lymphocyte separation medium (Corning, Corning, NY) and cultured in 6-well plates overnight in RPMI-1640. The next day, the nonadherent cells were harvested and saved and the adherent cells were pulsed with MHC class I restricted synthetic peptides $(50 \mu \mathrm{g})$ $+\beta 2$ microglobulin $(1.5 \mu \mathrm{g})$ in order to selectively expand epitope specific $\mathrm{CD}^{+} \mathrm{T}$ lymphocytes (CTLs). After a twohour incubation, the nonadherent cells were resuspended in a cytokine rich medium of RPMI-1640 supplemented with IL-7 (5 ng/mL), GM-CSF ( $25 \mathrm{ng} / \mathrm{mL})$, IL-4 $(50 \mathrm{ng} / \mathrm{mL})$, and keyhole limpet hemocyanin ( $5 \mathrm{ug} / \mathrm{mL}$ KLH; Sigma-Aldrich). The nonadherent cells were added back into the 6-well plates to a final volume of $5 \mathrm{~mL} /$ well and cultured at $37^{\circ} \mathrm{C}$ at $5 \% \mathrm{CO}_{2}$. $\mathrm{T}$ cells in culture were restimulated 12-14 days after initial stimulation with autologous PBMCs depleted of $\mathrm{CD} 4^{+}$and $\mathrm{CD}^{+} \mathrm{T}$ cells and pulsed with synthetic peptides $(10 \mathrm{ug} / \mathrm{mL})$ and $\beta 2$-microglobulin $(1.5 \mathrm{ug} / \mathrm{mL})$. Restimulated cells were cultured in RPMI-1640 supplemented with IL-15 $(5 \mathrm{ng} / \mathrm{mL})$, GM-CSF $(12.5 \mathrm{ng} / \mathrm{mL})$, and IL-2 $(10 \mathrm{U} / \mathrm{mL})$ for 7 days. Restimulation was performed a total of three times prior to CTL functional assays. Unless otherwise specified, all cytokines and growth factors were purchased from eBiosciences (San Diego, CA).
2.7. Generation of Epitope Specific CTLs In Vivo. All transgenic mouse manipulations (i.e., injections and spleen harvests) were carried out at Lampire Biologicals. HLA-A2 ${ }^{+}$ and HLA-A $24^{+}$transgenic mice were injected with PBS alone or 10 ug of synthetic peptides in PBS or a 50:50 emulsion with Montanide ISV 51 (Seppic Inc, Fairfield, NJ). Mice were injected at two sites: subcutaneously (s.c.) on the flank and intradermally (i.d.) near the base of the tail. Mice received a total of three injections, at 10 days intervals. A week after the third injection, mice were euthanized and the spleens were harvested for use in $\mathrm{T}$ cell functional assays.

2.8. ELISpot Assays. 96-well PVDF-membrane plates (Millipore) were coated with IFN-gamma capture antibody overnight at $4^{\circ} \mathrm{C}$. On the day of the assay, the plates were blocked for 2 hours in RPMI-1640 complete medium and washed prior to use in the ELISpot assay. In vitro generated CTLs were assayed 7 days after the final restimulation. Peptide specific CTLs were harvested, counted, and cultured overnight with appropriate antigen presenting cells that were unpulsed or pulsed with synthetic peptides (T2 or HepG2 cells) or antigen presenting cells that are productively infected with HBV (HepDE19, HepG2.2.15, and 293/T/A2 Ad-HBV infected cells). The next day the assay was developed according to the manufacturer's instructions (BD Biosciences, San Jose, CA). In vivo generated CTLs were assayed 7 days after the final peptide injection. Spleens were harvested and homogenized into a single cell suspension. After lysis of RBCs, the cells were extensively washed, counted, and cultured overnight with HepG2 cells unpulsed or pulsed with synthetic peptides or HepDE19 cells. The next day the assay was developed according to the manufacturer's instructions (BD Biosciences). For both ELISpot assays, spots were quantified using the ELISpot Reader System (AID, San Diego, CA).

2.9. MAGPIX Cytokine Detection. Cytokine secretion from activated $\mathrm{CD}^{+} \mathrm{T}$ cells was measured using a customized MILLIPLEX magnetic bead assay according to manufacturer's instructions (Millipore). Briefly, supernatants were harvested from $\mathrm{CD}^{+} \mathrm{T}$ cells stimulated with various targets and cleared of cellular debris by a brief centrifugation. $25 \mu \mathrm{L}$ of samples, standards, and controls was added to a 96-well plate containing assay buffer (1:1 dilution). Next, magnetic beads coated with antibodies against the cytokines being analyzed were added to each well. The plate was then sealed and incubated on a plate shaker overnight at $4^{\circ} \mathrm{C}$. The next day, the plate was washed twice with wash buffer and biotinylated detection antibodies were added. The plate was sealed again and rocked for 1 hour at RT followed by the addition of streptavidin-PE for additional 30 minutes. The plate was washed twice with wash buffer, loaded with sheath fluid, and read on the MAGPIX system. Data was analyzed with Milliplex Analyst software according to manufacturer's instructions (Luminex, Austin, TX).

2.10. Flow Cytometry Analysis. To detect epitope specific, cytotoxic $\mathrm{CD}^{+} \mathrm{T}$ cells $\left(\mathrm{CD}^{+} \mathrm{CD}^{+} 107 \mathrm{a}^{+}\right)$, splenocytes derived 

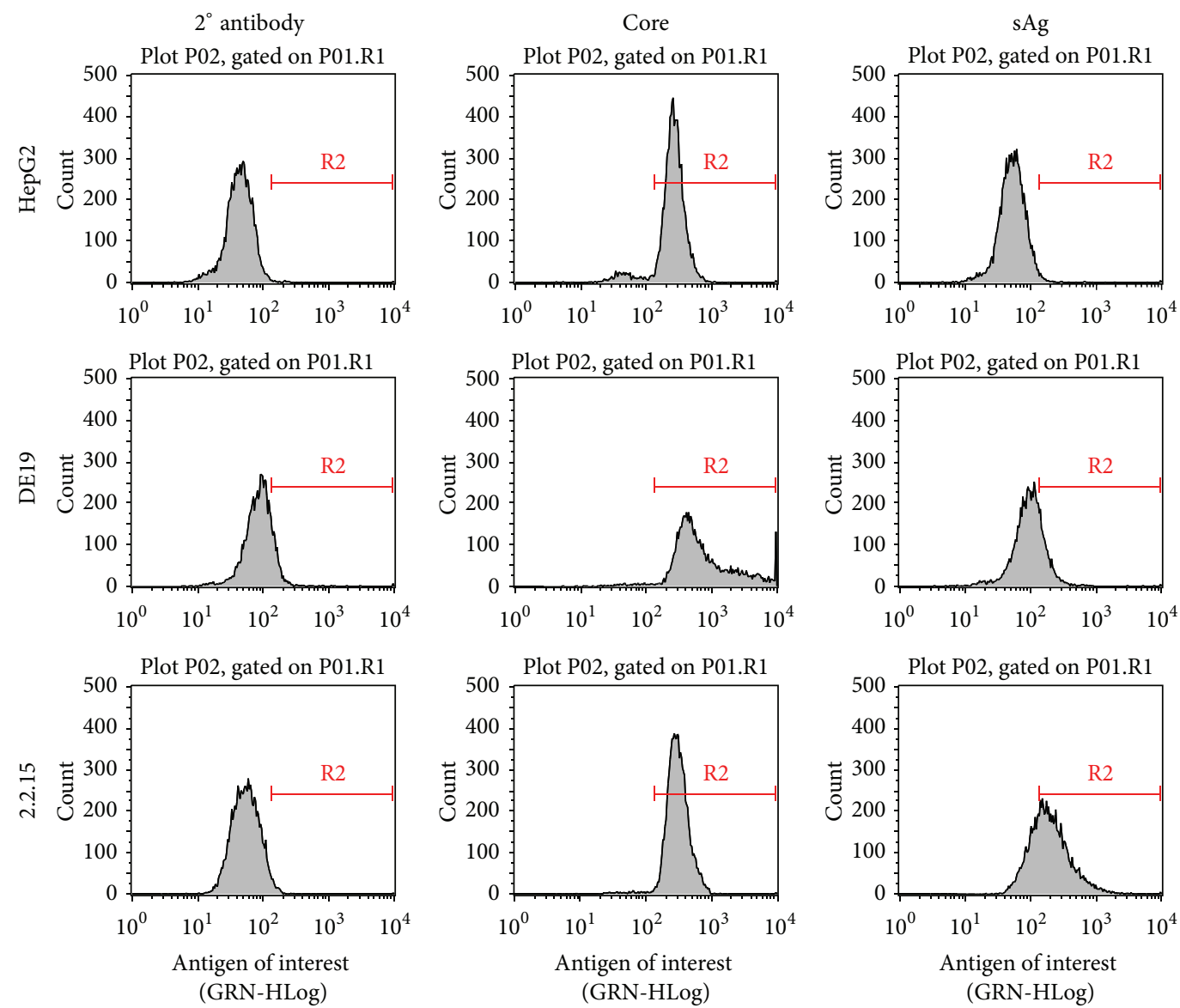

(a)
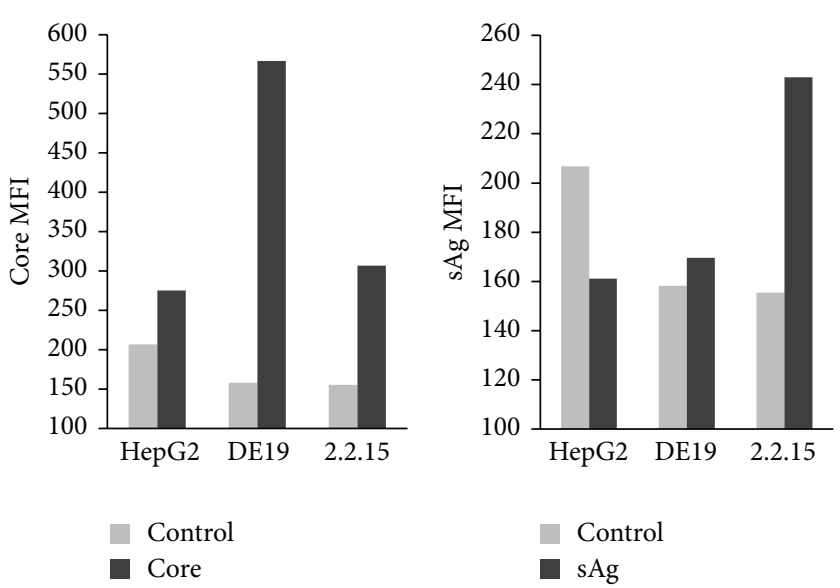

(b)

FIGURE 2: HBV protein expression in infected cell lines. (a) HepG2, DE19 (lacks sAg), and 2.2.15 (complete HBV genome) were harvested, fixed and permeabilized, and stained with HBV specific antibodies directed against core or sAg. (b) Median fluorescent intensity (MFI) derived from the flow plots shown in (a).

from peptide primed mice were cultured with HepG2 cells left unpulsed or pulsed with specific peptides or with HepDE19 cells for six hours in the presence of anti-CD107a-PE (BD Biosciences). After six hours, cells were washed and $\mathrm{CD} 8^{+} \mathrm{T}$ cells were detected by addition of anti-CD $8 \alpha$-FITC (eBiosciences). For verification of infectivity, HepG2, HepDE19, HepG2.2.15, or $293 \mathrm{~T} / \mathrm{A} 2 / \mathrm{HBV}$ cells were washed, fixed, and permeabilized with the Cytofix/Cytoperm kit according to manufacturer's instructions (BD Biosciences). Cells were incubated with antibodies against $\mathrm{HBV}$ core (Abcam, Cambridge, MA) or HBV sAg (Santa Cruz Biotechnology, Dallas, TX) for 30 minutes at RT. Following extensive washes with permeabilization wash buffer, cells were incubated with anti-mouse IgG FITC conjugated secondary antibody (BD Biosciences) 
TABLE 1: HBV specific MHC class I restricted peptides identified by immunoproteomics. The LC-MS/MS selection criteria for peptides are as follows: Charge 1: Xcorr > 1.6; Charge 2: Xcorr > 1.8; Charge 3: Xcorr > 2.0. The HLA binding scores were calculated using the SYFPEITHI prediction program [28].

\begin{tabular}{lccccccc}
\hline Peptide sequence & Protein & Accession ID & HLA motif & $\mathrm{m} / z$ & Charge & Xcorr & HLA binding score \\
\hline GGPNLDNIL & Large E & Q8QSF2 & A2 & 457 & 2 & 1.88 & 13 \\
LTFGRETVLEN & Precore/core (C) & Q6UFV9 & A2 & 640 & 2 & 2.18 & 19 \\
LTTVPAASLLA & Large E & Q9YKJ7 & A2 & 530 & 2 & 2.12 & 20 \\
ILRSFIPLL & Surface (S) & Q6WYY8 & A2/24 & 537 & 2 & 1.81 & A2: 28; A24: 12 \\
FLKQQYMNL & Polymerase (P) & I0DE20 & A2/24 & 1185 & 1 & 1.92 & A2: 20; A24: 9 \\
FLSKQYMDL & Polymerase (P) & L7QBE1 & A2/A24 & 573 & 2 & 1.80 & A2: $21 ;$ A24: 11 \\
TVSTKLCKI & Polymerase (P) & Q8B4E6 & A2/A24 & 497 & 2 & 1.92 & A2: $19 ;$ A24: 14 \\
FLGGPPVCL & Surface (S) & Q0EED2 & A2/A24 & 452 & 2 & 2.05 & A2: 26; A24: 11 \\
\hline
\end{tabular}

for 20 minutes at RT. Cells were washed extensively and resuspended in $\mathrm{PBS} / 0.1 \%$ BSA before acquiring. All flow cytometry events were acquired on the Guava easyCyte 8HT (Millipore). Data was analyzed using InSight software on the guavaSoft 2.6 platform (Millipore).

\section{Results}

3.1. Identification of MHC Class I Presented Epitopes from Hepatitis B Virus Infected Cells by Nano LC/MS/MS Methods. $\mathrm{T}$ cell therapeutic vaccines are an attractive treatment option for individuals chronically infected with hepatitis B virus. In order for a therapeutic vaccine to induce sustained $\mathrm{T}$ cell responses, it must include antigens that are naturally processed and presented by the infected cells. Therefore, we set out to identify naturally processed and presented $\mathrm{HBV}$ specific MHC class I restricted epitopes using an immunoproteomics approach. In this approach, peptides associated with MHC class I molecules are isolated from the infected cells and identified using mass spectrometry analysis [2027] (Figure 1). Peptide/MHC complexes were isolated from cells chronically expressing HBV antigens (HepDE19 and HepG2.2.15) and cells infected with an adenovirus encoding for the HBV genome (293T/A2-AdHBV). Using multiple cell types was essential because it allowed for identification of epitopes from the complete genome (e.g., HepDE19 do not express surface $\mathrm{Ag}(\mathrm{sAg})$ ) (Figure 2). Using stringent mass spectra search criteria, we identified eight novel MHC-I peptide epitopes with high confidence: three HLA-A2 restricted peptides (GGP; LTF; LTT) and five peptides (ILR; FLK; FLS; TVS; FLG) that show promiscuity to binding both HLA-A2 and HLA-A24 (Table 1). The HLA binding affinities of the peptides calculated using the SYFPEITHI algorithm ([28] accessed via http://www.syfpeithi.de/) showed variable binding scores (Table 1). We then confirmed the sequence identity of these epitopes using synthetic analogs. The MS/MS spectra of the synthetic epitopes matched the spectra of the experimentally identified epitopes nearly identically (Figure 3 ). In addition to these novel epitopes, we identified 19 MHC-I restricted peptides derived from HBV that have been previously described by motif prediction method with low mass spec Xcorr search criteria that do not meet our established standards for high abundance and confidence and therefore were not included in our assays (see Table 1 in Supplementary Materials available online at http://dx.doi.org/10.1155/2014/860562).

3.2. Epitopes Identified by Immunoproteomics Analysis Activate $H B V$ Specific CTLs In Vitro. After confirming the sequence of the experimentally identified epitopes, we determined if these epitopes could activate $\mathrm{CD} 8^{+} \mathrm{T}$ cells. To do so, we generated epitope specific CTLs from PBMCs isolated from healthy HLA-A2 ${ }^{+}$donors using the synthetic peptide versions. Epitope specific $\mathrm{CD} 8^{+} \mathrm{T}$ cells were activated (as measured by IFN-gamma ELISpot) when cultured with T2s pulsed with peptide (Figure 4(a)) and with HepDE19 or 293-T/A2-AdHBV cell lines (Figure 4(b)). Importantly, these responses were specific as only background $\mathrm{CD}^{+}{ }^{+} \mathrm{T}$ cell activation was observed when the cells were cultured with normal liver, uninfected HepG2, or uninfected 293T/A2 cells (Figure 4(b)). Furthermore, the CTL responses did not correlate with their HLA binding affinities (Table 1).

3.3. Epitopes Identified by Immunoproteomics Analysis Activate HBV Specific CTLs In Vivo. After establishing that epitopes could specifically induce $\mathrm{CD}^{+} \mathrm{T}$ cell activation in vitro, we next sought to determine if the experimentally identified peptides could also stimulate $\mathrm{CD} 8^{+} \mathrm{T}$ cells in vivo. Because a subset of our peptides (ILR; FLK; FLS; TVS; FLG) had the motif to bind both HLA-A2 and HLA-A24 molecules, we assessed $\mathrm{CD}^{+} \mathrm{T}$ cell activation of these peptides in both HLA contexts. Synthetic versions of these peptides were injected into HLA-A $2^{+}$or HLA-A $24^{+}$transgenic mice with or without Montanide ISV-51 adjuvant, three times in total. One week after the third injection, splenocytes were harvested and cultured with HepG2 cells pulsed individually with peptides alone or HBV infected cells in an IFN-gamma ELISPot assay. As shown in Figure 5(a), $\mathrm{CD}^{+}{ }^{+} \mathrm{T}$ cells generated in vivo specifically recognized peptide loaded HepG2 cells as well as HBV infected HepDE19 cells. In addition, CD8 ${ }^{+} \mathrm{T}$ cells generated in vivo also upregulated a classical marker of degranulation (CD107a) [29, 30] after stimulation with both peptide pulsed HepG2s and HBV chronically infected cell line HepDE19 (Figure 5(b)). Interestingly, the peptides induced IFN-gamma secretion and CD107a upregulation independent of the HLA molecule tested which indicates that 

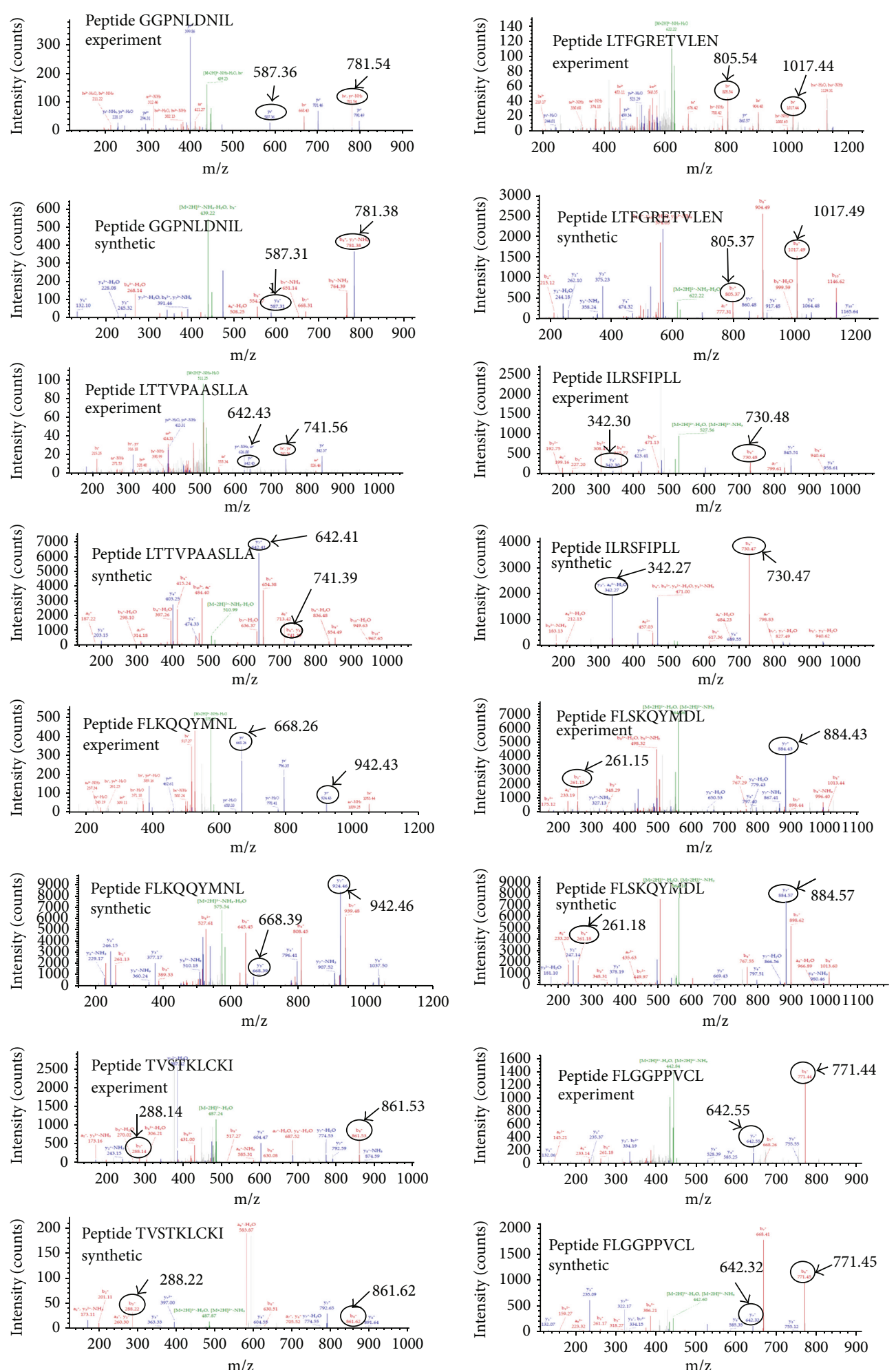

FIGURE 3: Validation of naturally presented MHC peptides from HBV infected cells. Mass spectrometry (MS/MS) spectra of the experimentally identified peptides (top spectra) versus their synthetic analogs (bottom spectra). Fragment masses that match are denoted.

these HLA-A2 and HLA-A24 double binding peptides are capable of activating both HLA-A2 and HLA-A24 specific T cell responses.

Because degranulation is associated with delivery of perforin and granzyme to target cells, we next checked the levels of granzyme B being secreted by the peptide activated CD $8^{+}$ $T$ cells. Supernatants were collected from the stimulated cells and the levels of granzyme B were detected using Milliplex magnetic bead technology $[31,32]$. $\mathrm{CD}^{+} \mathrm{T}$ cells from both HLA-A2 and HLA-A24 immunized mice secreted high levels 


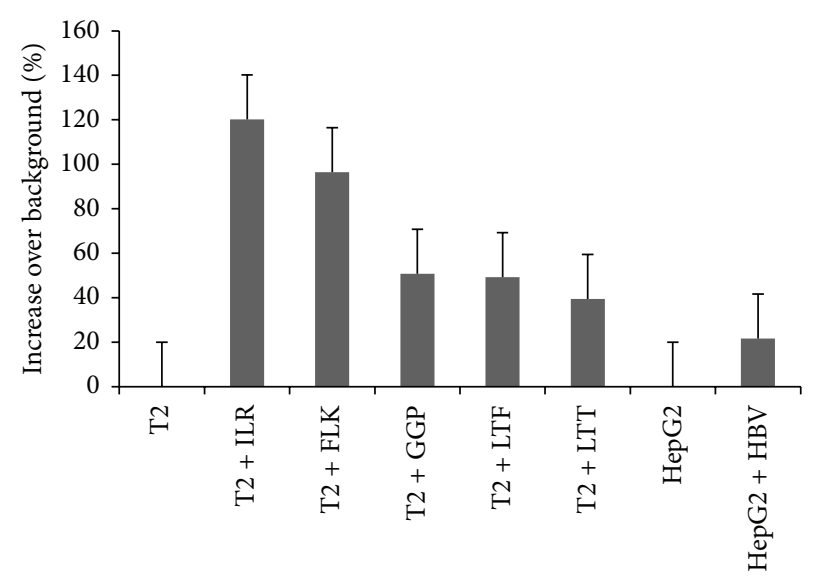

(a)

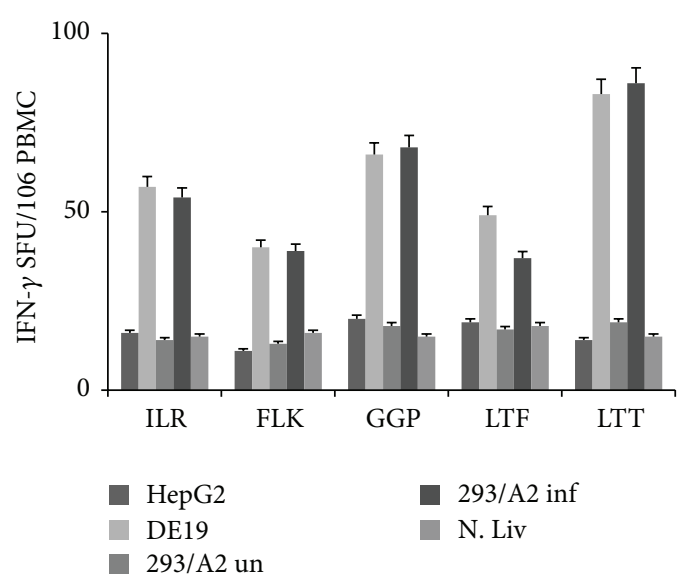

(b)

FIgURE 4: HBV specific peptides stimulate $\mathrm{CD} 8^{+} \mathrm{T}$ cell activation in vitro. (a) HLA-A2 restricted CTLs directed against the identified peptides (peptides are represented as first 3 residues of the sequence) were generated using peripheral blood from healthy donors. PBMCs containing the epitope specific CTLs were harvested, washed, and cultured with the peptide pulsed or HBV expressing cells overnight in an IFN-gamma ELISpot assay. Data is represented as \% increase over background. (b) PBMCs containing epitope specific CTLs were harvested, washed, and cultured with uninfected or HBV expressing cells overnight in an IFN-gamma ELISpot assay. Normal liver cells served as a negative, nonspecific control.

of granzyme-B in response to peptide stimulation and $\mathrm{HBV}$ chronically infected HepDE19 cell stimulation compared to their naïve counterparts indicating the activation of a specific cytotoxic response (Figure 6).

\section{Discussion}

The peptides described in this report are newly identified epitopes and, to our knowledge, have not been reported elsewhere. Importantly, these peptides were derived from multiple viral proteins, thereby potentially increasing the targets for $\mathrm{T}$ cells and inducing the broad response needed for chronic viral clearance. Two peptides (GGP and LTT) are derived from the large E protein, one (LTF) is derived from the core protein, two (ILR and FLG) are derived from surface protein, and three (FLK; FLS; TVS) are derived from the polymerase protein. The diversity of our identified peptides is similar to that of the response induced during a natural infection (reviewed in [3]). Previous studies in HLA-A2 restricted models have identified immunodominant epitopes from core protein (HBc18-27; [11, 19]), envelope and polymerase proteins (HBe 348-357, HBp455-463; [19]), and $\mathrm{X}$ protein $(\mathrm{HBx} 4-10 ;[33])$. Although we were able to detect a few of these peptides in our analysis (including the clinically well studied HBcAg 18-27 epitope, FLPSDFFPSV), the scores (Xcorr values) obtained from MS/MS analysis did not meet standard abundance and confidence cutoff criteria for inclusion in our assays (Supplementary Table 1). A few potential explanations exist to clarify this observation. First, although a subset of these peptides was shown to induce $T$ cell activation in patients acutely infected with HBV [19], T cell responses generated during acute HBV infections may very well differ from those necessary to clear virus during a chronic infection due to alterations in MHC peptide repertoire on chronically infected cells. Differences in epitope specificity between acute and chronic phases of infection have been observed in other models of chronic infections, for example, LCMV $[34,35]$ and HIV-1 [36]. Secondly, the low confidence epitopes identified may not be presented at very high levels on the surface of the chronically infected cells, which would lead to a low representation in the MS/MS analysis. Interestingly, several recent reports have demonstrated that low level antigen presentation preferentially favors the expansion of naïve but not memory $\mathrm{CD}^{+} \mathrm{T}$ cells [37-39], which may explain the transient (not sustained) increases in these epitopes specific $\mathrm{CD}^{+} \mathrm{T}$ cell responses in previous clinical trials. Together these data indicate that low scoring peptides may not be the right target for inclusion in therapeutic vaccines and the most relevant targets should be identified by analyzing chronically infected cells.

In order to identify epitopes that are naturally processed and presented by chronically infected cells, we utilized an immunoproteomic approach. Using this approach, we identified eight novel MHC class I restricted epitopes that are derived from four different proteins of the HBV genome. We first confirmed that the identified peptides were able to induce $\mathrm{CD}^{+} \mathrm{T}$ cell activation by measuring IFN-gamma production in an ELISpot assay. Importantly, the $\mathrm{T}$ cells were able to recognize the naturally processed and presented epitope appearing on a variety of $\mathrm{HBV}$ infected cells regardless of their HLA binding affinities (Table 1). Interestingly, five out of eight peptides that we have characterized contained the appropriate motifs to bind both the HLA-A2 and HLA-A24 supertypes (http://www.hiv.lanl.gov/content/immunology/motif_scan/ supertype.html). HLA-A2 supertype is prevalent in $>40 \%$ of the world population and HLA-A24 supertype is prevalent in $>50 \%$ of $\mathrm{HBV}$ endemic population 


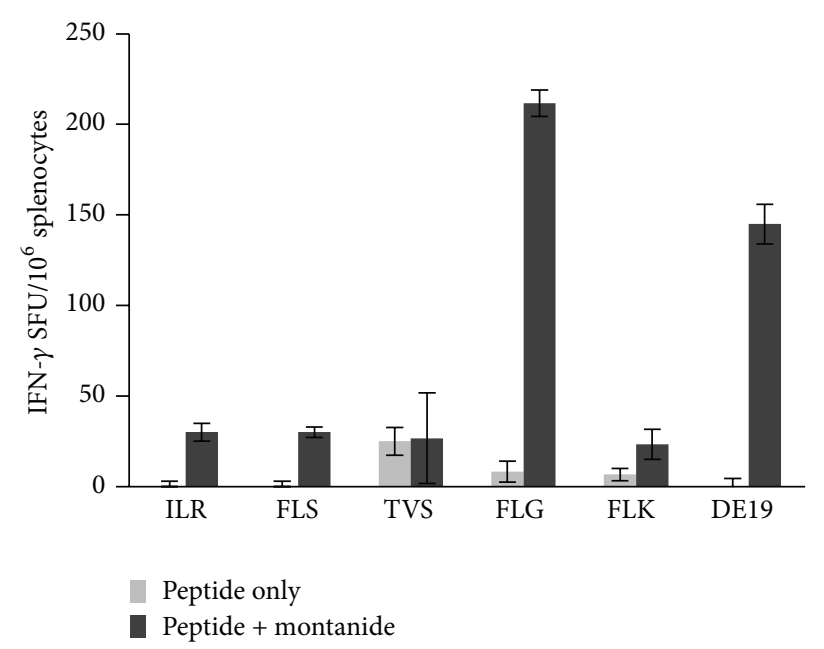

(a)

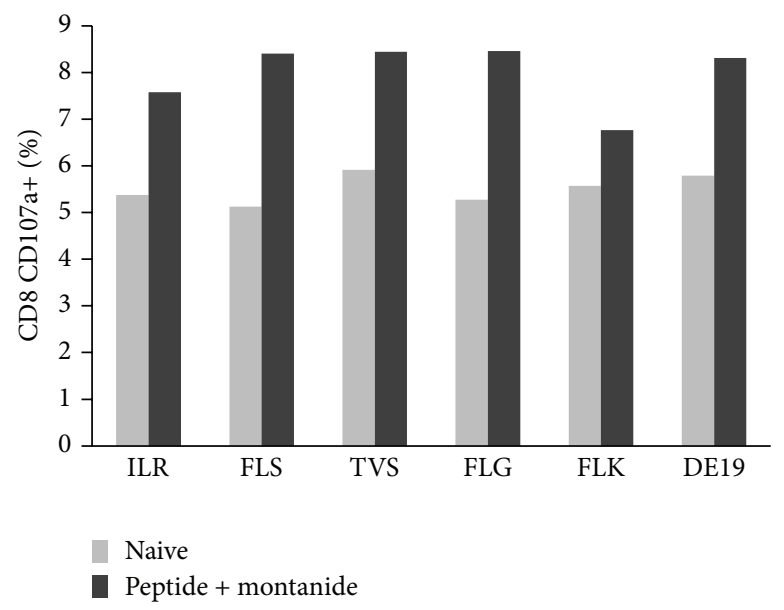

(c)

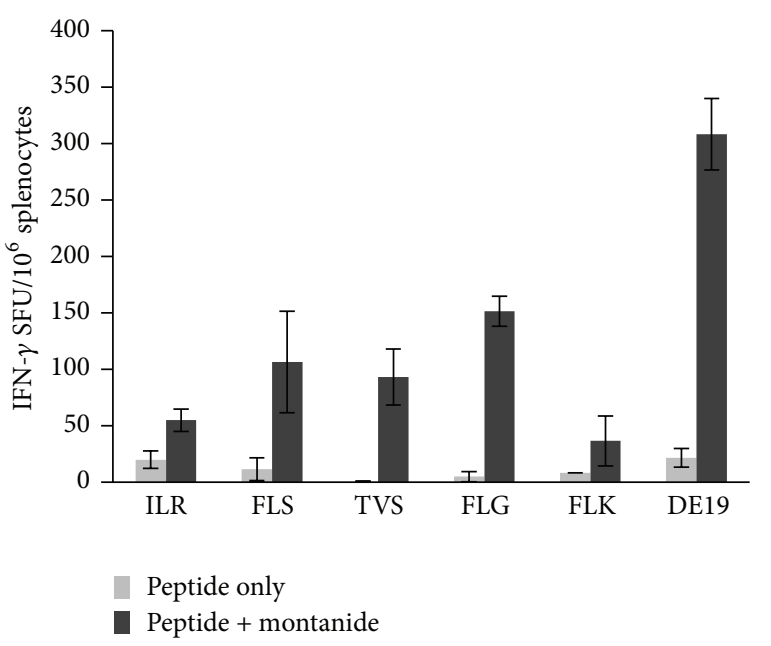

(b)

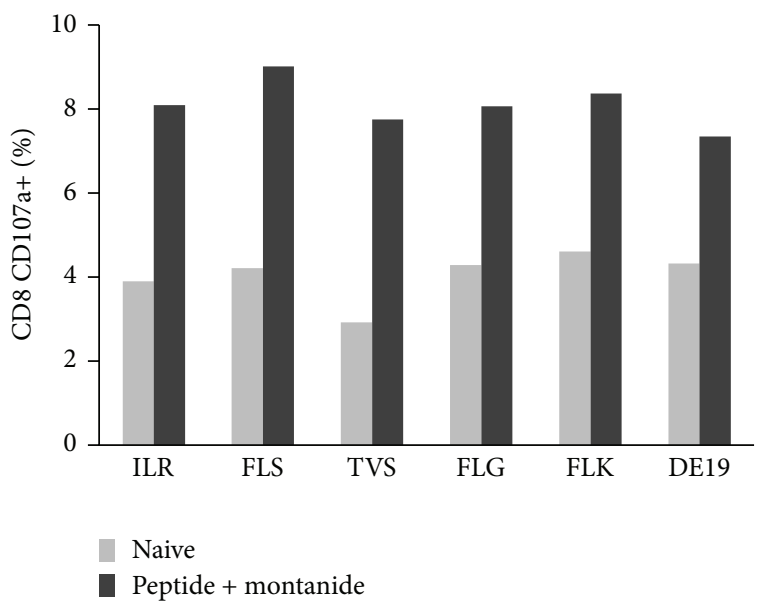

(d)

Figure 5: HBV specific peptides are able to activate $\mathrm{CD}^{+} \mathrm{T}$ cells in vivo in both an HLA-A2 and HLA-A24 restricted fashion. HLA-A2 (a) or HLA-A24 (b) transgenic mice were primed and boosted with peptides as previously described. Spleens were harvested, homogenized into single cell suspensions, and cultured with peptide pulsed (peptides are represented as first 3 residues of the sequence) HepG2 cells or HBV expressing cells overnight in an IFN-gamma ELISpot assay. T cell activation was also measured by examining CD107a upregulation on HLAA2 (c) or HLA-A24 (d) CD8 ${ }^{+}$T cells. Splenocytes were cultured for 6 hours with peptide pulsed or HBV expressing cells in the presence of anti-CD107a and subsequently stained for $\mathrm{CD}^{+}$expression. Data is presented as the percent of cells in culture that are $\mathrm{CD} 8^{+} \mathrm{CD} 107 \mathrm{a}^{+}$.

(http://www.allelefrequencies.net/). Indeed, in vivo experiments using mice transgenic for the HLA-A2 or HLA-A24 molecule demonstrated that these peptides can induce $\mathrm{T}$ cell activation (as measured by IFN-gamma secretion) and cytolytic activity (as measured by CD107a upregulation and granzyme B secretion) in both A2 and A24 restricted manner.

Thus far, the large majority of epitope discovery for HBV has relied on peptide motif prediction software that estimates how well peptides bind to MHC class I molecules. Strong binders are selected and verified by using synthetic versions to stimulate $\mathrm{T}$ cells of both uninfected and infected individuals. However, peptides predicted to bind to the class I molecule may not accurately represent the epitopes presented on the surface of naturally infected cells in vivo, nor is a positive binding score a guarantee that $\mathrm{T}$ cells will be activated (unpublished observations). As such, differences in epitope identification approaches will undoubtedly lead to different immunodominant hierarchies being established. For example, Gehring et al. [40] demonstrated that, relative to other immunodominant epitopes (i.e., HBc18-27), T cell specific responses against polymerase epitopes are low. In contrast, our data indicates that, for the epitopes identified by the immunoproteomic approach, the polymerase specific $\mathrm{T}$ cells respond just as robustly (in terms of IFN-gamma secretion and granzyme B secretion) as those specific for core and envelope peptides.

Clearance of viral infections such as hepatitis B virus and hepatitis $\mathrm{C}$ virus is driven by rapid and robust $\mathrm{CD} 4^{+}$ and $\mathrm{CD}^{+} \mathrm{T}$ cell responses. Not surprisingly, individuals who become chronically infected do not mount these vigorous responses $[2,3,9,41,42]$. Therefore, any therapeutic intervention to stimulate viral clearance in chronically infected patients must activate a robust, sustained $\mathrm{T}$ cell 


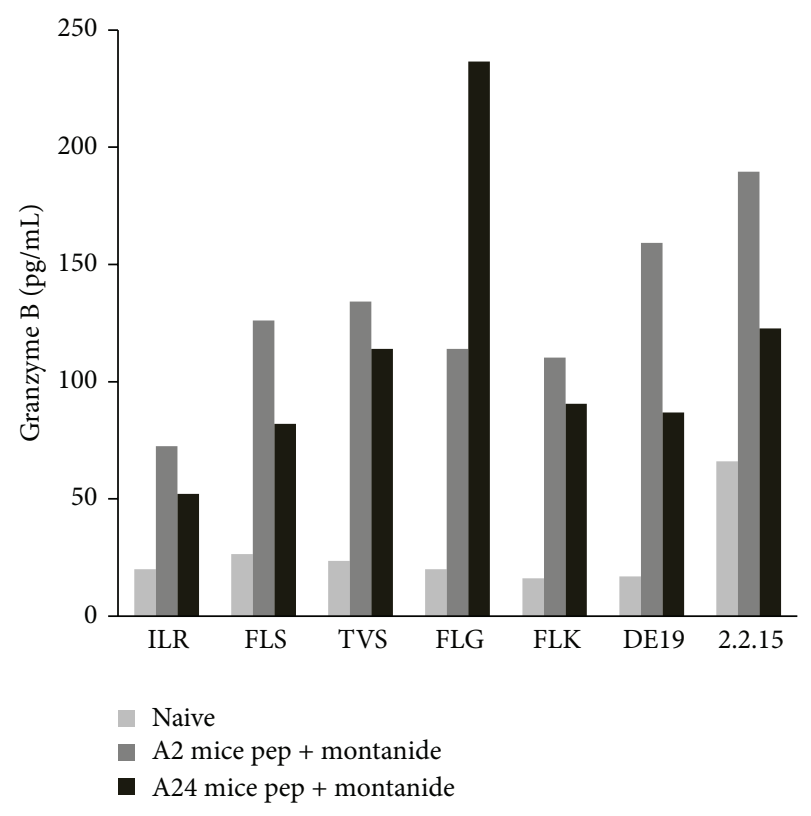

FIgUre 6: $\mathrm{HBV}$ peptide specific $\mathrm{CD}^{+} \mathrm{T}$ cells activated in vivo secrete cytotoxic effector molecules. In an assay that mirrored the setup described in Figure 5, splenocytes were cultured with peptide pulsed (peptides are represented as first 3 residues of the sequence) or HBV expressing cells overnight. Supernatant was harvested and used in the Milliplex magnetic bead assay to detect granzyme B secretion in response to specific stimulation. Splenocytes from PBS primed, naïve mice were used as a negative control.

response directed at a diverse range of epitopes processed and presented by the chronically infected cell. A number of therapeutic vaccines for HBV have been studied in animal and human models. Although these therapeutic vaccine formulations have stimulated T cells [16-18, 43-45], sustained responses were not achieved $[17,46]$ and it is unclear from these studies if the $\mathrm{T}$ cell responses induced are capable of clearing virus from chronically infected patients. The lack of clinical responses may be due to the fact that the $\mathrm{T}$ cell responses induced by these therapies may not accurately reflect the epitopes that are presented by the chronically infected cells. Therefore, formulating an effective therapeutic vaccine for chronic infections should include those epitopes that are naturally processed and presented by the chronically infected cells.

Currently, there is no effective therapeutic vaccine or other immunotherapy to treat chronic HBV infected individuals. The large majority of epitope discovery by motif analysis for hepatitis B virus has been done in HLA-A2 restricted systems. Although HLA-A2 allele represents $>40 \%$ of the world population, the HLA-A24 allele is more prevalent in HBV endemic population. There are no reliable algorithms for predicting HLA-A2 and A24 binding peptides. However, to design a more universal therapeutic vaccine, multiple HLA restricted epitopes need to be identified. Using an immunoproteomic approach, it is possible to purify multiple HLA alleles from the same HBV infected cell lysate and subject the isolated peptides to MS/MS analysis without a significant increase in workload or difficulty. Additionally, this approach can identify epitopes that can bind to more than one HLA allele. In our study, we identified naturally presented HBV specific $\mathrm{T}$ cell epitopes with double HLA binding properties, which have the potential to form the basis for a therapeutic vaccine appropriate for the HBV endemic population. Five of the identified peptides reported here share motifs that allow binding to HLA-A2 and HLA-A24 and activation of $\mathrm{CD}^{+} \mathrm{T}$ cells in both settings. Including epitopes that bind to single, distinct HLA alleles and epitopes that bind to multiple HLA alleles in a vaccine formulation may overcome HLA differences between patient populations, increase the breadth of the $\mathrm{T}$ cell response, and prevent escape due to antigen downregulation. These (and other) novel MHC class I binding epitopes can readily be incorporated into therapeutic vaccine formulations and tested in preclinical experiments prior to being tested in human clinical trials.

\section{Conclusions}

Our finding of novel HLA-A2 and A24-associated peptides from HBV infected cells and demonstration of HBV specific CTL responses broadens the applicability of the immunoproteomics methodology and provides candidate antigens for the development of immunotherapeutic vaccines for the treatment of chronic HBV infection. The data presented in this paper is preliminary and extensive preclinical data is needed to develop these antigens into a therapeutic vaccine.

\section{Conflict of Interests}

The authors declare that there is no conflict of interests regarding the publication of this paper.

\section{References}

[1] A. S. F. Lok and B. J. McMahon, “Chronic hepatitis B," Hepatology, vol. 34, no. 6, pp. 1225-1241, 2001.

[2] B. Rehermann and M. Nascimbeni, "Immunology of hepatitis B virus and hepatitis C virus infection," Nature Reviews Immunology, vol. 5, no. 3, pp. 215-229, 2005.

[3] A. Bertoletti and A. J. Gehring, "The immune response during hepatitis B virus infection," Journal of General Virology, vol. 87, part 6, pp. 1439-1449, 2006.

[4] C. W. Shepard, E. P. Simard, L. Finelli, A. E. Fiore, and B. P. Bell, "Hepatitis B virus infection: epidemiology and vaccination," Epidemiologic Reviews, vol. 28, no. 1, pp. 112-125, 2006.

[5] D. Lavanchy, "Hepatitis B virus epidemiology, disease burden, treatment, arid current and emerging prevention and control measures," Journal of Viral Hepatitis, vol. 11, no. 2, pp. 97-107, 2004.

[6] L. G. Guidotti, T. Ishikawa, M. V. Hobbs, B. Matzke, R. Schreiber, and F. V. Chisari, "Intracellular inactivation of the hepatitis B virus by cytotoxic T lymphocytes," Immunity, vol. 4, no. 1, pp. 25-36, 1996.

[7] L. G. Guidotti, R. Rochford, J. Chung, M. Shapiro, R. Purcell, and F. V. Chisari, "Viral clearance without destruction of infected cells during acute HBV infection," Science, vol. 284, no. 5415, pp. 825-829, 1999. 
[8] R. Thimme, S. Wieland, C. Steiger et al., " $\mathrm{CD} 8^{+} \mathrm{T}$ cells mediate viral clearance and disease pathogenesis during acute hepatitis B virus infection," Journal of Virology, vol. 77, no. 1, pp. 68-76, 2003.

[9] J. J. Chang and S. R. Lewin, "Immunopathogenesis of hepatitis B virus infection," Immunology and Cell Biology, vol. 85, no. 1, pp. 16-23, 2007.

[10] G. J. M. Webster, S. Reignat, M. K. Maini et al., "Incubation phase of acute hepatitis B in man: dynamic of cellular immune mechanisms," Hepatology, vol. 32, no. 5, pp. 1117-1124, 2000.

[11] C. Ferrari, A. Penna, A. Bertoletti et al., "Cellular immune response to hepatitis $B$ virus-encoded antigens in acute and chronic hepatitis B virus infection," Journal of Immunology, vol. 145, no. 10, pp. 3442-3449, 1990.

[12] B. Rehermann, P. Fowler, J. Sidney et al., "The cytotoxic T lymphocyte response to multiple hepatitis B virus polymerase epitopes during and after acute viral hepatitis," Journal of Experimental Medicine, vol. 181, no. 3, pp. 1047-1058, 1995.

[13] C. P. Desmond, A. Bartholomeusz, S. Gaudieri, P. A. Revill, and S. R. Lewin, "A systematic review of T-cell epitopes in hepatitis $B$ virus: identification, genotypic variation and relevance to antiviral therapeutics," Antiviral Therapy, vol. 13, no. 2, pp. 161175, 2008.

[14] B. Rehermann, D. Lau, J. H. Hoofnagle, and F. V. Chisari, "Cytotoxic T lymphocyte responsiveness after resolution of chronic hepatitis B virus infection," The Journal of Clinical Investigation, vol. 97, no. 7, pp. 1655-1665, 1996.

[15] D.-Z. Xu, K. Zhao, L.-M. Guo et al., "A randomized controlled phase IIb trial of antigen-antibody immunogenic complex therapeutic vaccine in chronic hepatitis B patients," PLoS ONE, vol. 3, no. 7, Article ID e2565, 2008.

[16] B. D. Livingston, C. Crimi, H. Grey et al., "The hepatitis B virus-specific CTL responses induced in humans by lipopeptide vaccination are comparable to those elicited by acute viral infection," Journal of Immunology, vol. 159, no. 3, pp. 1383-1392, 1997.

[17] M. Mancini-Bourgine, H. Fontaine, D. Scott-Algara, S. Pol, C. Bréchot, and M.-L. Michel, "Induction or expansion of T-cell responses by a hepatitis B DNA vaccine administered to chronic HBV carriers," Hepatology, vol. 40, no. 4, pp. 874-882, 2004.

[18] P. Pancholi, D.-H. Lee, Q. Liu et al., "DNA prime/canarypox boost-based immunotherapy of chronic hepatitis B virus infection in a chimpanzee," Hepatology, vol. 33, no. 2, pp. 448-454, 2001.

[19] A. Sette, A. Vitiello, B. Reherman et al., "The relationship between class I binding affinity and immunogenicity of potential cytotoxic T cell epitopes," Journal of Immunology, vol. 153, no. 12, pp. 5586-5592, 1994.

[20] J. S. Testa, V. Shetty, J. Hafner et al., "MHC class I-presented $\mathrm{T}$ cell epitopes identified by immunoproteomics analysis are targets for a cross reactive influenza-specific T cell response," PLoS ONE, vol. 7, no. 11, Article ID e48484, 2012.

[21] J. S. Testa, V. Shetty, G. Sinnathamby et al., "Conserved MHC class I-presented dengue virus epitopes identified by immunoproteomics analysis are targets for cross-serotype reactive T-cell response," The Journal of Infectious Diseases, vol. 205, no. 4, pp. 647-655, 2012.

[22] V. Shetty, Z. Nickens, J. Testa, J. Hafner, G. Sinnathamby, and R. Philip, "Quantitative immunoproteomics analysis reveals novel MHC class I presented peptides in cisplatin-resistant ovarian cancer cells," Journal of Proteomics, vol. 75, no. 11, pp. 3270-3290, 2012.
[23] V. Shetty, G. Sinnathamby, Z. Nickens et al., "MHC class Ipresented lung cancer-associated tumor antigens identified by immunoproteomics analysis are targets for cancer-specific $\mathrm{T}$ cell response," Journal of Proteomics, vol. 74, no. 5, pp. 728-743, 2011.

[24] K. T. Hogan, M. A. Coppola, C. L. Gatlin et al., "Identification of a shared epitope recognized by melanoma-specific, HLA-A3restricted cytotoxic T lymphocytes," Immunology Letters, vol. 90, no. 2-3, pp. 131-135, 2003.

[25] S. Feyerabend, S. Stevanovic, C. Gouttefangeas et al., "Novel multi-peptide vaccination in Hla-A2+ hormone sensitive patients with biochemical relapse of prostate cancer," Prostate, vol. 69, no. 9, pp. 917-927, 2009.

[26] O. E. Hawkins, R. S. Vangundy, A. M. Eckerd et al., "Identification of breast cancer peptide epitopes presented by HLAA*0201," Journal of Proteome Research, vol. 7, no. 4, pp. 1445$1457,2008$.

[27] K. T. Hogan, M. A. Coppola, C. L. Gatlin et al., "Identification of novel and widely expressed cancer/testis gene isoforms that elicit spontaneous cytotoxic T-lymphocyte reactivity to melanoma," Cancer Research, vol. 64, no. 3, pp. 1157-1163, 2004.

[28] H.-G. Rammensee, J. Bachmann, N. P. N. Emmerich, O. A. Bachor, and S. Stevanović, "SYFPEITHI: database for MHC ligands and peptide motifs," Immunogenetics, vol. 50, no. 3-4, pp. 213-219, 1999.

[29] M. R. Betts, J. M. Brenchley, D. A. Price et al., "Sensitive and viable identification of antigen-specific $\mathrm{CD}^{+} \mathrm{T}$ cells by a flow cytometric assay for degranulation," Journal of Immunological Methods, vol. 281, no. 1-2, pp. 65-78, 2003.

[30] E. A. Mittendorf, C. E. Storrer, C. D. Shriver, S. Ponniah, and G. E. Peoples, "Evaluation of the CD107 cytotoxicity assay for the detection of cytolytic $\mathrm{CD}^{+}$cells recognizing HER2/neu vaccine peptides," Breast Cancer Research and Treatment, vol. 92, no. 1, pp. 85-93, 2005.

[31] A. Parmigiani, M. L. Alcaide, R. Freguja et al., "Impaired antibody response to influenza vaccine in HIV-infected and uninfected aging women is associated with immune activation and inflammation," PLoS ONE, vol. 8, no. 11, Article ID e79816, 2013.

[32] J. K. Nieminen, M. Niemi, T. Sipponen et al., "Dendritic cells from Crohn's disease patients show aberrant STAT1 and STAT3 signaling," PLoS ONE, vol. 8, no. 8, Article ID e70738, 2013.

[33] S. Malmassari, Y. C. Lone, M. Zhang, C. Transy, and M.-L. Michel, "In vivo hierarchy of immunodominant and subdominant HLA-A* 0201- restricted T-cell epitopes of HBx antigen of hepatitis B virus," Microbes and Infection, vol. 7, no. 4, pp. 626634, 2005.

[34] E. J. Wherry, J. N. Blattman, K. Murali-Krishna, R. Van Der Most, and R. Ahmed, "Viral persistence alters CD8 Tcell immunodominance and tissue distribution and results in distinct stages of functional impairment," Journal of Virology, vol. 77, no. 8, pp. 4911-4927, 2003.

[35] R. G. van der Most, K. Murali-Krishna, J. G. Lanier et al., "Changing immunodominance patterns in antiviral CD8 T-cell responses after loss of epitope presentation or chronic antigenic stimulation," Virology, vol. 315, no. 1, pp. 93-102, 2003.

[36] P. J. R. Goulder, M. A. Altfeld, E. S. Rosenberg et al., "Substantial differences in specificity of HIV-specific cytotoxic T cells in acute and chronic HIV infection," Journal of Experimental Medicine, vol. 193, no. 2, pp. 181-193, 2001.

[37] E. R. Jellison, M. J. Turner, D. A. Blair et al., "Distinct mechanisms mediate naive and memory CD8 T-cell tolerance," 
Proceedings of the National Academy of Sciences of the United States of America, vol. 109, no. 52, pp. 21438-21443, 2012.

[38] M. D. Martin, S. A. Condotta, J. T. Harty, and V. P. Badovinac, "Population dynamics of naive and memory CD8 T cell responses after antigen stimulations in vivo," Journal of Immunology, vol. 188, no. 3, pp. 1255-1265, 2012.

[39] E. R. Mehlhop-Williams and M. J. Bevan, "Memory CD8 ${ }^{+}$T cells exhibit increased antigen threshold requirements for recall proliferation," The Journal of Experimental Medicine, vol. 211, no. 2, pp. 345-356, 2014.

[40] A. J. Gehring, D. Sun, P. T. F. Kennedy et al., “The level of viral antigen presented by hepatocytes influences CD8 T-cell function," Journal of Virology, vol. 81, no. 6, pp. 2940-2949, 2007.

[41] F. Lechner, D. K. Wong, P. R. Dunbar et al., "Analysis of successful immune responses in persons infected with hepatitis C virus," The Journal of Experimental Medicine, vol. 191, no. 9, pp. 1499-1512, 2000.

[42] N. H. Shoukry, A. G. Cawthon, and C. M. Walker, "Cellmediated immunity and the outcome of hepatitis $\mathrm{C}$ virus infection," Annual Review of Microbiology, vol. 58, pp. 391-424, 2004.

[43] A. Vitiello, G. Ishioka, H. M. Grey et al., "Development of a lipopeptide-based therapeutic vaccine to treat chronic HBV infection. I. Induction of a primary cytotoxic T lymphocyte response in humans," The Journal of Clinical Investigation, vol. 95, no. 1, pp. 341-349, 1995.

[44] R. Schirmbeck, P. Riedl, N. Fissolo, F. A. Lemonnier, A. Bertoletti, and J. Reimann, "Translation from cryptic reading frames of DNA vaccines generates an extended repertoire of immunogenic, MHC class I-restricted epitopes," Journal of Immunology, vol. 174, no. 8, pp. 4647-4656, 2005.

[45] P. Buchmann, C. Dembek, L. Kuklick et al., "A novel therapeutic hepatitis $\mathrm{B}$ vaccine induces cellular and humoral immune responses and breaks tolerance in hepatitis B virus (HBV) transgenic mice," Vaccine, vol. 31, no. 8, pp. 1197-1203, 2013.

[46] S. Pol, B. Nalpas, F. Driss et al., "Efficacy and limitations of a specific immunotherapy in chronic hepatitis B," Journal of Hepatology, vol. 34, no. 6, pp. 917-921, 2001. 


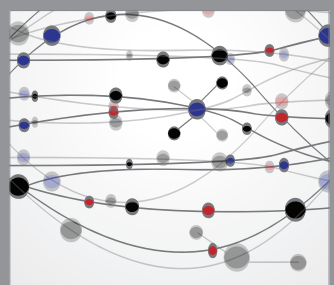

The Scientific World Journal
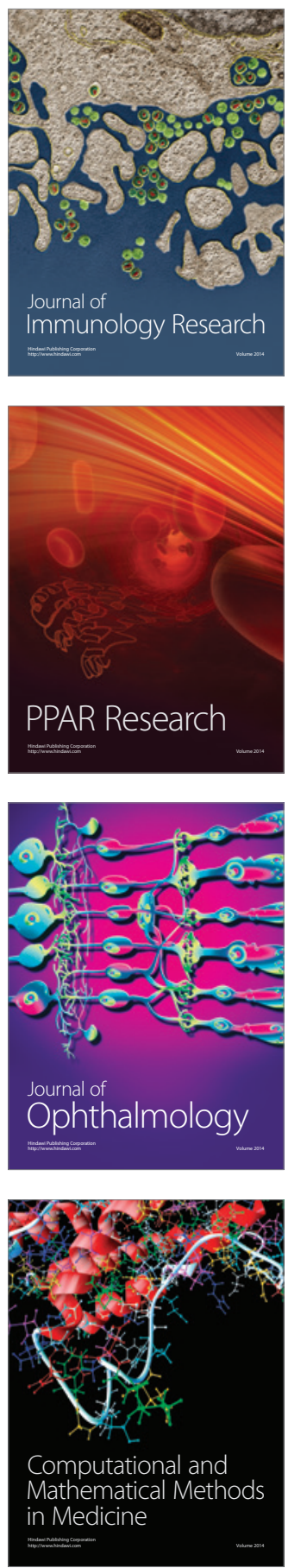

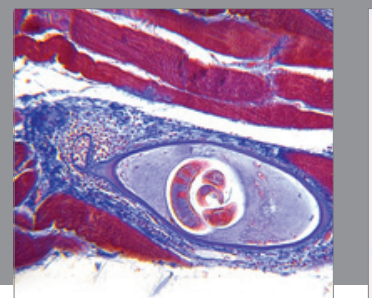

Gastroenterology

Research and Practice
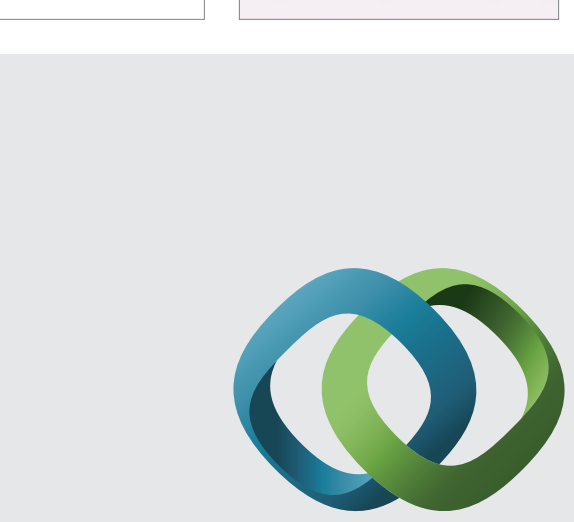

\section{Hindawi}

Submit your manuscripts at

http://www.hindawi.com
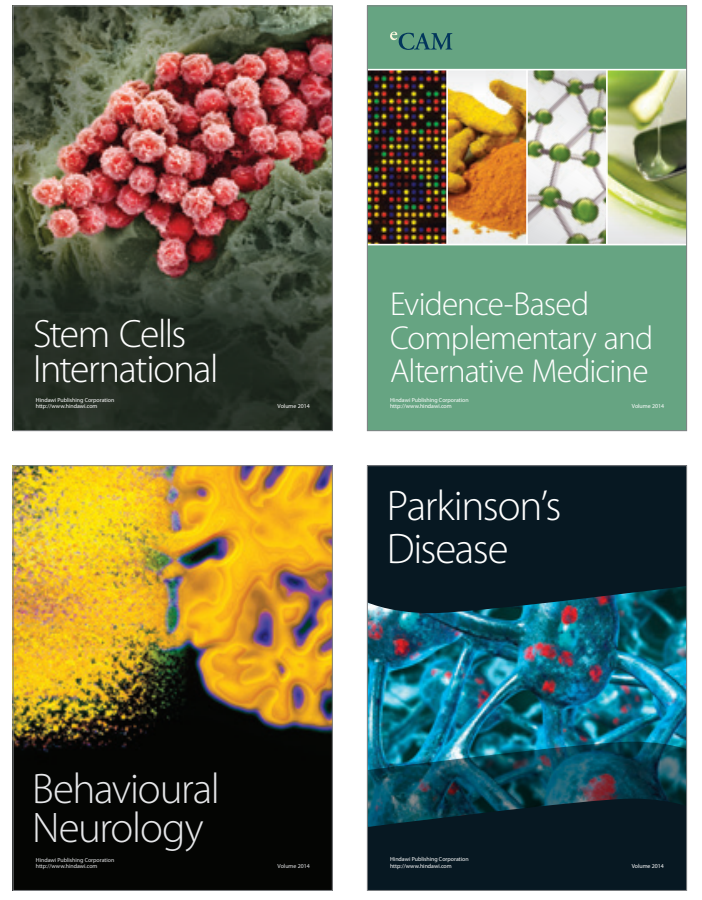
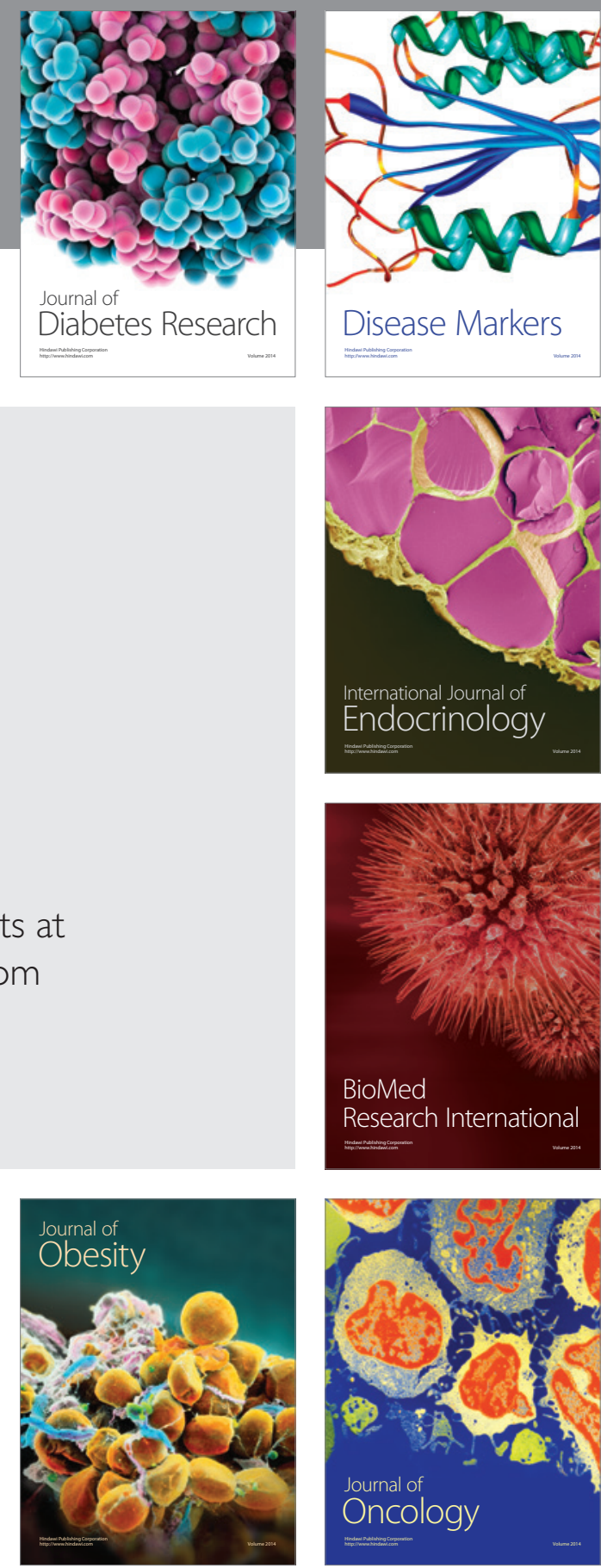

Disease Markers
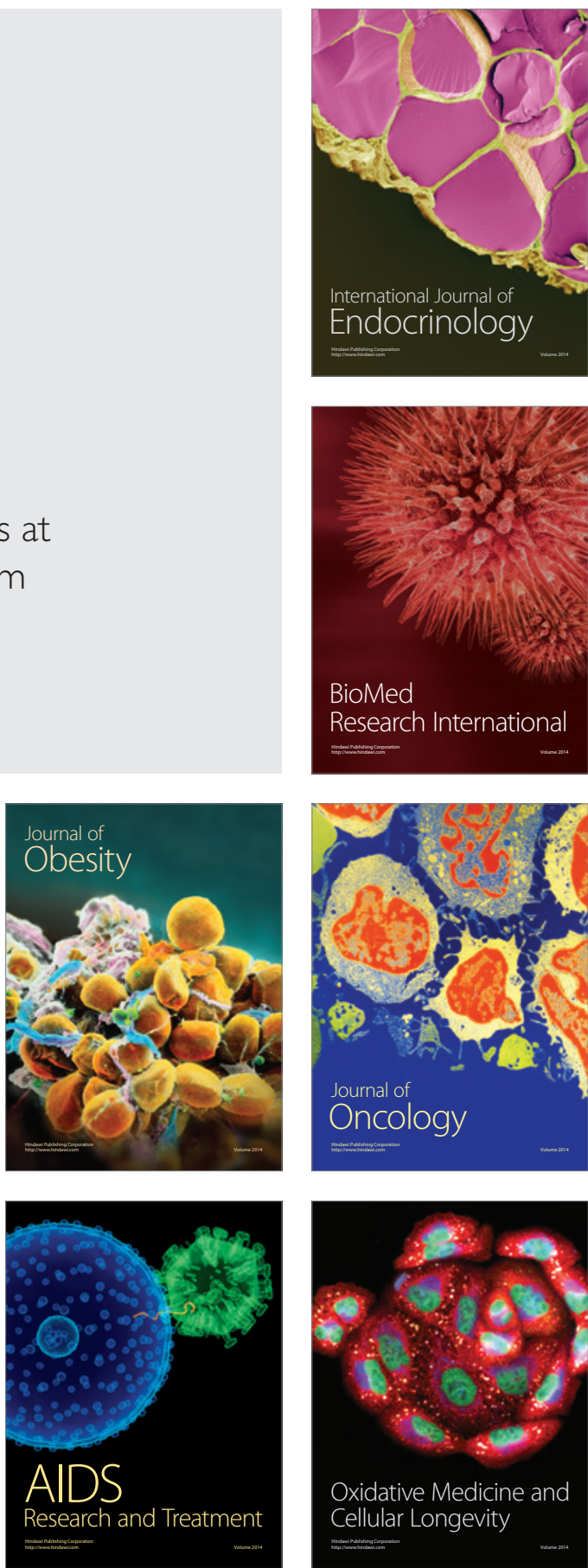